\title{
DE LA NARRATIVA DEL ESTEREOTIPO A LA NARRATIVA DEL SILENCIO: CÓMO SE HA CONTADO LA HISTORIA DE EDICIONES RIALP, S. A. (1948-2018)*
}

\author{
POR \\ Mercedes Montero díaz $Z^{1}$ \\ Universidad de Navarra
}

\section{RESUMEN}

El artículo se centra en el análisis histórico de Ediciones Rialp, S.A. y en las dos narrativas más importantes desarrolladas por la historiografía española en torno a su proyecto cultural. Al mismo tiempo, se estudian sus relaciones con el Opus Dei y la influencia que este hecho haya podido tener en la elaboración de las narrativas descritas. Simultáneamente, se propone una nueva manera de afrontar la historia de esta empresa cultural que cumple ya más de 70 años, y es la única de su tiempo que conserva tanto la independencia como la línea editorial.

PALABRAS CLAVE: Ediciones Rialp, S. A.; narrativas históricas; Opus Dei; España; 1948-2018.

\section{FROM THE NARRATIVE OF THE STEREOTYPE TO THE NARRATIVE OF SILENCE: HOW THE STORY OF EDICIONES RIALP, S.A. (1948-2018) HAS BEEN TOLD}

\begin{abstract}
The article focuses on the historical analysis of Ediciones Rialp, S.A. and in the two most important narratives developed by Spanish historiography around its cultural project. At the same time, their relations with Opus Dei are studied and the influence that this fact may have had in the elaboration of the described narratives. Simultaneously, a new way of facing the history of this cultural company that is already more than 70 years old is proposed. Rialp is the only one of its time that preserves both the independence and the editorial line.
\end{abstract}

KEY WORDS: Rialp Editions, S. A.; Historical Narratives; Opus Dei; Spain; 1948-2018.

Cómo CITAR ESTE ARTículo / CITATION: Montero Díaz, Mercedes. 2021. «De la narrativa del estereotipo a la narrativa del silencio: cómo se ha contado la historia de Ediciones Rialp, S. A. (1948-2018)». Hispania Sacra LXXIII, 147: 273-287. https://doi. org/10.3989/hs.2021.023

$\begin{array}{lr}\text { Recibido/Received } & 21-03-2019 \\ \text { Aceptado/Accepted } & 27-07-2020\end{array}$

\section{FUENTES Y METODOLOGÍA PARA LA HISTORIA DE EDICIONES} RIALP, S. A.

En 2018 se cumplieron setenta años de vida de Ediciones Rialp, S. A. ${ }^{2}$ Un hecho insólito en el panorama del libro

* Este artículo es resultado del proyecto concedido por el Ministerio de Economía y Competitividad: DER2016-76619-P Narrativas en conflicto: libertad religiosa y relaciones iglesia- estado en los siglos XIX y XX.

mmontero@unav.es /

ORCID iD: https://orcid.org/0000-0001-6992-4023

2 En 1948 se constituyó la sociedad anónima. Pero desde el otoño de 1946 funcionaba ya de hecho con Florentino Pérez-Embid a frente. Abreviaturas utilizadas: AGP=Archivo General de la Prelatura español, porque la empresa ha celebrado el aniversario desde una trayectoria de apuesta firme y constante por su línea editorial y, como consecuencia, de independencia. Todo ello a pesar de haber sufrido en tres ocasiones graves crisis cercanas al cierre. Por trances similares han pasado otras compañías del sector, con prestigio y calidad, que perdieron por el camino la vida o la identidad. Solamente por haberse librado de este final aciago, merecía la pena dedicarle atención al proyecto cultural de Ediciones Rialp.

de la Santa Cruz y Opus Dei. Roma, Italia (Fondo Ediciones Rialp, S.A.); AGA=Archivo General de la Administración (Fondo Ediciones Rialp, $S$. S.); AGUN=Archivo General de la Universidad de Navarra (Fondo Ediciones Rialp, S.A. Fondo Rafael Calvo Serer). 
Pero es que además esta no se ha limitado a subsistir en el tiempo por pura inercia, si ello fuera posible en el ámbito editorial; al contrario, ha sido una empresa muy comprometida con la aportación de ideas en su entorno socio cultural, a menudo a contracorriente de lo que bullía alrededor. Y también aguza el interés del investigador las relaciones que pudo tener o no tener con el Opus Dei. A este conjunto de cuestiones intentaremos dar respuesta en el presente artículo.

Sobre historia del libro y la edición en España se han escrito investigaciones sumamente interesantes, muchas de ellas publicadas por la Editorial Trea, S. A., especializada en esta materia. ${ }^{3}$ Sin embargo, como también ocurre o ha ocurrido en otros ámbitos (por ejemplo, en la comunicación) no suelen abordarse en esos trabajos la trayectoria en el tiempo, desde su fundación al de día de hoy, de las empresas individuales que lograron hacer historia con su actividad. En comunicación, área igualmente conformadora de la opinión pública y del andamiaje cultura de un país, esa carencia fue subsanada con el tiempo y las monografías sobre empresas periodísticas concretas; empieza a lograrse ahora en el sector audiovisual, con aportaciones acerca de la historia de compañías televisivas y radiofónicas; pero todavía brilla por su ausencia en el ámbito de la publicidad. Algo similar ocurre con la edición. Salvo libros autobiográficos de editores, que aportan datos muy variados sobre sus actividades (más o menos anecdóticas, más o menos esenciales), no existen investigaciones rigurosas centradas en alguna empresa editorial concreta, en si misma considerada. Abunda el género de 'libro-entrevista' a editores importantes, ciertas memorias más o menos impresionistas, algunas actividades divulgativas del mundo editorial a las que luego se ha dado forma de libro, con las intervenciones de los ponentes... pero nada referido a cualquier empresa cuyo objetivo haya sido la 'fabricación' de libros... ${ }^{4}$

Además de las obras referenciados en el texto y en las notas a pie de página, para realizar este artículo se ha consultado el archivo de la propia editorial y los archivos personales de Rafael Calvo Serer y Florentino Pérez-Embid, custodiados los tres fondos en el Archivo General de la Universidad de Navarra (AGUN); el Archivo General de la Prelatura de la Santa Cruz y Opus Dei (AGP), que se encuentra en Roma y que contiene un fondo sobre Ediciones Rialp que aporta información relevante; y por último, el Archivo General de la Administración (AGA), en Alcalá de Henares, donde se puede consultar la documentación del periodo en que existió el Ministerio de Información y Turismo y cuyas exigencias obligaban tanto a las empresas periodísticas como a las editoriales.

La metodología por la que se ha apostado ha sido el estudio, el contraste y la visión crítica de las fuentes consultadas. La abundancia de fondos procedentes de archivo, fuentes inéditas o conocidas pero poco estudiadas; la biblio-

\footnotetext{
3 Entre otros, se pueden citar las siguientes obras, utilizadas para contextualizar este artículo: láñez 2011; Larraz 2010; Ruiz Bautista 2005 y 2008; Sánchez Vigil 2009; Escobar Laplana 2012; Martínez de Sousa 2015.

4 Entre las obras leídas para este trabajo y que certifican lo que venimos diciendo, podemos citar las siguientes: Soler 2006; Escolar Sobrino 1999; Lago Carballo 2004; Lago Carballo y Gómez Villegas 2006; Martínez Martín 2015; Moret 2002; Tusquets 2005; Barral 1982; Cruz Ruiz 2014; Herralde 2001; Salinas 2013; Pérez Escohotado 2002.
}

grafía; las entrevistas orales... todo ello ha estado en función de entender el porqué de la existencia (y pervivencia) actual de Rialp; el porqué de sus éxitos y fracasos; y, por supuesto, el nivel de sus relaciones con el Opus Dei, variables a lo largo de su historia. Como es lógico, la editorial se ha encontrado en contacto con los problemas habituales del sector del libro en España, desde las penurias económicas, las condenas políticas o eclesiásticas, o las aventuras y desventuras en Hispanoamérica. Por ello se hacen breves referencias a otras empresas del mismo ámbito, que no pueden ser más amplias pues pondría en peligro la coherencia de la línea narrativa. Su relación con el Opus Dei acaba resultando el aspecto clave. Pero - es necesario subrayarlo- tampoco el trabajo es sobre esta institución de la Iglesia Católica, por lo que las líneas de acción de Rialp y del Opus Dei no son tratadas con igual detenimiento. Es evidente que lo que ocurra en la Obra va a afectar a Rialp, en no pocas ocasiones; pero en otras muchas, no. Por lo tanto, no me he detenido en ello más de lo necesario, sin pretender adentrarme en la historia del Opus Dei, como tampoco lo he hecho en historias compartidas por la editorial con otros actores: el gobierno del cardenal Segura en Sevilla, el ministerio de Ruiz-Giménez, o la historia de otras editoriales españolas.

Las cuestiones de las que vengo hablando han sido estudiadas en los documentos de archivo, en las fuentes orales y en la tradición historiográfica española sobre el mundo editorial, las polémicas intelectuales, etc. El estudio y el análisis riguroso y comparativo de estas fuentes es lo que ha hecho posible llegar a entender, de un modo lógico y articulado, el porqué de las preguntas planteadas al comienzo de la investigación. El resultado ha sido una propuesta de narrativa histórica sobre Rialp y dos críticas sobre las que ahora existen. Ambas han 'recibido un nombre' que puede definir - aunque sea parcialmente- su manera de proceder.

\section{UNA PROPUESTA DE NARRATIVA PARA EDICIONES RIALP}

Ediciones Rialp fue consecuencia de un anhelo del fundador del Opus Dei, Josemaría Escrivá de Balaguer, que ya soñaba con algo parecido desde antes de la guerra civil. ${ }^{5}$ En 1943 pareció encontrar a una persona que podía sacar adelante su ilusión de publicar libros de calidad, también en el ámbito espiritual, editados con buen gusto, agradables a la vista, que animaran a la gente a leer. Libros que fueran respetuosos con las convicciones católicas de quienes las tenían. Esa persona fue María Natividad Jiménez Salas, ${ }^{6}$ una

González Gullón 2016, 76-77.

María Natividad Jiménez Salas (Zaragoza, 1910 - Madrid, 1999) era hija de Inocencio Jiménez, uno de los fundadores de la corriente de la democracia cristiana en España, y Juana Salas. El padre fue buen amigo de Escrivá. Ocupó la cátedra de Derecho Penal y Procesal en la Universidad Central de Madrid y perteneció a la Junta de Ampliación de Estudios antes de la guerra civil. Uno de sus hijos frecuentó en los años treinta la Academia-Residencia DYA, primera iniciativa apostólica puesta en marcha por Escrivá. Terminada la contienda, Inocencio Jiménez formó parte, como presidente, del tribunal académico que juzgó la tesis doctoral en Derecho Civil del fundador del Opus Dei. Falleció en 1941. Por su parte, Juana Salas fue una destacada activista por los derechos de la mujer en las organizaciones femeninas católicas (Blasco 2007, 187-207). Natividad Jiménez Salas trabajaba en el Consejo Superior de Investigaciones Científicas (CSIC) como vicesecretaria de la revista Arbor. Estudió en Zaragoza antes de la guerra civil y se instaló en Madrid con su familia después de la contienda. Escribió el libro Vida 
mujer que nunca perteneció a la Obra. La editorial se llamó Minerva, por referencia a la diosa de la sabiduría, duró tres años, publicó tres libros y hubo de echar el cierre por falta de sentido comercial. ${ }^{7}$ Mientras tanto otro personaje se entusiasmó con el posible proyecto, Florentino Pérez-Embid, ${ }^{8}$ un joven que acababa de pedir la admisión en el Opus Dei y que hizo de la editorial un empeño suyo personal. Esta cambió el nombre porque Minerva resultó denominación repetida, y pasó a llamarse Rialp. Si algo caracterizó los comienzos de esta empresa cultural fue la apertura mental, la que se podía tener - no podemos olvidarlo- en la España del momento. Quedaban en el país algunos liberales pero, sobre todo, existían varios grupos político-culturales (monárquicos, falangistas, carlistas, los llamados 'católicos oficiales') que se repartían la influencia en las instituciones públicas o fundaban sus propios organismos privados, casi siempre con el afán de prevalecer sobre los demás. PérezEmbid quería que en su editorial escribieran, tradujeran, prologaran o participaran, de una u otra manera, personalidades de valía intelectual, con independencia de su tendencia ideológica. Así Enrique Azcoaga ${ }^{9}$ — un liberal- dirigió la colección 'El carro de Estrellas'; José Luis Cano ${ }^{10}$-republicano más o menos tibio, agnóstico vital- siguió al frente de la colección de poesía 'Adonais', que él mismo había ideado; Rafael Calvo Serer, ${ }^{11}$ amigo personal de Pérez-Embid, y vol-

y obras de D. Juan Pablo Forner y Segarra (1944), por el que recibió el premio Duque de Alba de la Real Academia Española. Estuvo siempre vinculada al CSIC donde también publicó Historia de la asistencia socia en España en la Edad Moderna (1958) y Santa Teresa de Jesús: bibliografía fundamental. Con Josefina de la Maza dio a la imprenta Vida de San Juan de la Cruz. Conoció a Josemaría Escrivá en 1939, en casa de su familia

7 Montero 2017

Florentino Pérez-Embid Tello (Aracena, Huelva, 12.VI.1918 Madrid, 23.XII.1974) estudió en la facultad de Filosofía y Letras de la Universidad de Sevilla entre 1934 y 1936, cuando el estallido de la guerra civil le obligó a interrumpirlos. Con apenas 18 años se incorporó a la primera bandera de Falange de Huelva. Tras la guerra terminó sus estudios universitarios en 1940 logrando premio extraordinario. Se decantó por la carrera académica, centrando su interés en el arte manuelino portugués y en la baja edad media andaluza. Pidió la admisión en el Opus Dei en 1943, con 25 años. En 1945 defendió y publicó su tesis doctoral sobre La Marina andaluza en la Baja Edad Media. En marzo de 1949 obtuvo la cátedra de Historia de los Descubrimientos Geográficos en la Universidad de Sevilla y en 1951 en la de Madrid.

9 Enrique Azcoaga (Madrid, 1912-1985). Poeta, novelista, ensayista, crítico de arte y literatura. Adscrito al movimiento conocido como Generación del 36. Recibió el Premio Nacional de Poesía en 1933. A finales de los años cuarenta emigró a Argentina, abrumado por el ambiente de falta de libertad que había en España.

10 Joven poeta algecireño en aquellos momentos, de pasado republicano, perteneciente también a la Generación del 36. Era amigo personal de varios poetas del 27, como Luis Cernuda y Vicente Aleixandre.

11 Rafael Calvo Serer (1916/1989). Fue un estudiante brillante, que logró premio extraordinario en el bachillerato y además una beca para residir en el Colegio Mayor Burjasot, donde cursó el bachillerato superior y los estudios universitarios. Se matriculó en 1933 en Filosofía y Letras (sección Historia), convirtiéndose además en un seguidor entusiasta del grupo formado en torno a la revista monárquica Acción Española. Fue presidente regional de la Confederación de Estudiantes Católicos Españoles (CECE). Conoció al fundador del Opus Dei el día 17 de marzo de 1936 y pidió la admisión en la Obra el 22 de abril, durante un viaje de Escrivá a Valencia. Durante la guerra pasó unos meses enfermo, pero en agosto de 1937 le movilizó el ejército republicano, formó parte del batallón Garibaldi de las Brigadas Internacionales y fue nombrado miliciano de la cultura. Enfermó de nuevo y anduvo diez cán monárquico, menéndez pelayista y anti liberal, diseñó la 'Biblioteca del Pensamiento Actual'; y Raimundo Paniker ${ }^{12}$ - ya por entonces casi una celebridad - se encargó de la colección Patmos de espiritualidad. Los dos últimos pertenecían al Opus Dei y Paniker era sacerdote.

Las relaciones de Rialp con esta institución fueron bastante fluidas durante los primeros momentos. ${ }^{13}$ Escrivá siguió de cerca el desarrollo de la empresa, aunque nunca intervino en su gestión, ya fuera en cuestiones grandes o pequeñas: ni sugirió el nombre, ni ideó las colecciones, ni buscó los directores, ni aconsejó libros, ni aportó capital. Se limitó a comprobar que el trabajo estaba en marcha ${ }^{14}$ y él fue uno de los autores de la nueva editorial, ya que Rialp nació también con la ilusión de poder publicar en ella los libros de Josemaría Escrivá. ${ }^{15}$

Empresarialmente tuvo más protagonismo Álvaro del Portillo ${ }^{16}$ quien el 9 de enero de 1947 solicitó la inscripción

meses de hospital en hospital, hasta que en agosto de 1938 se le declaró inútil total para el servicio. Al terminar la contienda, se presentó a examen de los dos últimos cursos de carrera, en la convocatoria de septiembre de 1939 y obtuvo el premio extraordinario de licenciatura. Defendió su tesis doctoral, Menéndez Pelayo y la decadencia española, en agosto de 1940 en la Universidad de Madrid. En junio de 1942, consiguió la cátedra de Historia Moderna y Contemporánea de la Universidad de Valencia.

12 Raimundo Paniker Alemany (Barcelona, 1918 - Tavernet, 2010). Hijo de padre hindú y madre católica. Realizó sus estudios universitarios en Alemania. Doctor en Filosofía, Química y Teología, enseñó en las Universidades de Madrid, La Sapienza (Roma), Montreal, Harvard, Varanasi, Bangalore y Santa Bárbara (California). Pidió la admisión en el Opus Dei en 1940 y fue ordenado sacerdote en 1946. Abandonó la institución en 1966 y se incardinó en la diócesis de Varanasi (Uttar Pradesh, India). Pasó veinte años de su vida entre Estados Unidos e India. Su producción fue enorme. Publicó más de 40 libros en diferentes lenguas europeas y más de 900 artículos. En India estudió a fondo el hinduismo, dialogando con los investigadores y gurúes hindúes; a la vez, permaneció en contacto con grupos de investigación filosófica y teológica, tanto en India como en Europa y América. Pasó varios periodos en las montañas del Himalaya, viviendo en monasterios budistas. En 1987 volvió a Cataluña y se instaló en Tavernet, donde permaneció hasta su muerte. El funeral público y según la liturgia católica, por voluntad suya y de acuerdo con el Obispo de Vic, se celebró el 3 de septiembre de 2010 en Montserrat. En un momento determinado cambió su nombre y la grafía de su apellido: pasó a llamarse Raimon Panikkar. En este trabajo lo escribiremos como él mismo lo hacía en los años cuarenta y cincuenta: Raimundo Paniker.

13 Por ejemplo, AGP G-889-I RIALP, Correspondencia, 9-I-1947. Carta de Florentino Pérez-Embid a José María Escrivá, donde el primero informa sobre la marcha de la cuarta edición de Camino y la segunda de Santo Rosario. También AGP. G-8891, RIALP, Correspondencia: Carta de Florentino Pérez-Embid a Josemaría Escrivá, 6-III-1947, donde le cuenta con buen humor lo curioso que resulta tratar con poetas, refiriéndose seguramente a la colección 'Adonais'. Escribimos Adonais sin tilde porque en aquel momento $-y$ durante muchos años - no la llevaba.

14 AGP. G-889-I RIALP, Correspondencia, «Estado actual de la marcha de la colección», 6-II-1947, p. 1. Este escrito pone de manifiesto lo que venimos diciendo. Redactado por Pérez-Embid y enviado a Roma para información de Escrivá y Del Portillo, informaba sobre la situación de algunas colecciones, pero no pedía sugerencias. Se trataba de un plan editorial ambicioso, que se cumpliría solo en cierta medida en los años siguientes, pero que ya indicaba cierta estrategia editorial: se señalaban colecciones y directores, títulos y autores, buena parte de ellos proporcionados por Rafael Calvo Serer.

15 El primero fue la cuarta edición de Camino.

16 Álvaro del Portillo (Madrid, 1914 - Roma, 1994). Era doctor Ingeniero de Caminos, doctor en Historia y doctor en Teología. Se incorporó al Opus Dei en 1935. Recibió la ordenación sacerdotal el 25 de junio de 1944. Fue elegido sucesor de Escrivá de Balaguer en sep- 
de la marca Ediciones Rialp, S. A. en el registro de la propiedad industrial. ${ }^{17}$

Los primeros libros de Rialp salieron al mercado gracias a préstamos de familias o amigos. En general, durante los años cuarenta, privó en la industria editorial española lo que Martínez Martín denomina minifundismo, es decir, unas empresas muy pequeñas dependientes de estructuras artesanales y familiares. Hasta 1948 Rialp pudo considerarse como un elemento más de este entramado, moviéndose, como el resto de sus colegas, "en una situación límite de supervivencia para adaptarse a las nuevas circunstancias». ${ }^{18}$ No existía en el panorama editorial español un tejido empresarial compuesto por sociedades anónimas, salvo las que habían resistido la devastación que supuso la guerra. La mayor parte de los capitales desembolsados tras la contienda, para erigir nuevas editoriales, no llegaban al millón de pesetas $^{19}$ y Rialp iba a encontrarse en esos niveles de inversión, en su caso aún más reducidos.

La sociedad anónima se creó el día 14 de junio de 1948 en la notaría madrileña de Santiago Pelayo Hore. Ante él concurrieron Antonio Huerta Ferrer (en nombre y como apoderado de Álvaro del Portillo, que residía en Roma), Javier Domínguez Marroquín, ${ }^{20}$ Florentino Pérez-Embid y Amadeo de Fuenmayor. ${ }^{21}$ La escritura establecía, en primer lugar, que Álvaro del Portillo era dueño de una industria denominada Ediciones Rialp y que los comparecientes habían convenido la constitución de una compañía mercantil anónima que absorbía la mencionada industria del señor del Portillo. En consecuencia, quedaba creada la compañía mercantil anónima denominada Ediciones Rialp, S.A., domiciliada en Madrid, Claudio Coello 126, A, con un capital de un millón de pesetas, dividido y representado por mil acciones al portador de mil pesetas de valor nominal cada una.

En aquel momento se pusieron en circulación 745 acciones que quedaron suscritas en el mismo acto y su valor

tiembre de 1975. San Juan Pablo II lo consagró obispo el 6 de enero de 1991. Su beatificación tuvo lugar en Madrid el 27 de septiembre de 2014. Durante el Concilio Vaticano II fue nombrado perito y secretario de la comisión conciliar sobre la disciplina del clero, que elaboró el decreto Presbyterorum Ordinis

17 Oficina española de patentes y marcas. № 0197336(3). http:// sitadex.oepm.es/SitadexWS/index.jsp?numExp=M0197336. Consulta: 21-02-2019.

18 Martínez Martín 2015, 234

19 Martínez Martín 2015, 236

20 Xavier Domínguez Marroquín (Bilbao, 1922-1984). Conoció el Opus Dei en Madrid cuando vivió en la residencia de Jenner después de la guerra civil. Estudió Derecho y Filosofía y Letras, aunque tuvo que abandonarlo cuando murió su padre, para hacerse cargo de los negocios familiares. Se dedicó también al periodismo y a la escritura. Colaboró habitualmente en la prensa con el seudónimo de «Jeromín de Zugavi» y fue director de Radio Juventud de Vizcaya. Políticamente pertenecía a la 'vieja guardia' de Falange. En las elecciones de 1977 se presentó como candidato por Falange a la alcaldía de Bilbao. Era el único aspirante que sabía euskera.

${ }^{21}$ Amadeo de Fuenmayor Champín (Valencia, 18-XII-1915 Pamplona, 22-XI-2005). Pidió la admisión en el Opus Dei en 1939. En 1940 logró la licenciatura de Derecho en la Universidad de Valencia, con premio extraordinario. En 1941 defendió la tesis doctoral en la Universidad de Madrid, logrando igualmente premio extraordinario. En 1944 sacó la cátedra de Derecho Civil en la Universidad de Santiago de Compostela, donde permaneció entre 1944 y 1948. Se ordenó sacerdote en 1949. Fue una de las personas que más contribuyó a la puesta en marcha y desarrollo de la Universidad de Navarra. nominal totalmente desembolsado en la siguiente forma y proporción:

1. Álvaro del Portillo y Diez de Sollano suscribió 145 acciones (145 000 pesetas). Pero no lo hizo materialmente sino que, en pago de las mismas, aportaba a la nueva sociedad el conjunto de bienes, derechos y obligaciones, activo y pasivo que al día 31 de diciembre de 1947 constituían su antigua industria.

2. Florentino Pérez-Embid y Amadeo de Fuenmayor suscribieron cada uno 125 acciones por un valor nominal de 125000 pesetas, que ambos desembolsaron en metálico en ese momento.

3. El mayor accionista fue Xavier Domínguez Marroquín que suscribió 150 acciones por un valor de 150.000 pesetas que también quedaron desembolsadas.

4. Se pusieron en circulación 200 acciones para colocar en la forma, plazos y condiciones que acordara el consejo de administración.

5. Otras 254 acciones quedaron en cartera.

En el mismo acto se constituyó el consejo de administración: Domínguez Marroquín fue nombrado presidente, puesto que detentaba el mayor número de acciones; Florentino Pérez-Embid era vocal y Amadeo de Fuenmayor secretario. Pérez-Embid asumió, a la vez, el cargo de director-gerente de la empresa. ${ }^{22}$ Conviene destacar que este consejo de administración no tenía un presidente especialmente proclive a la 'nueva generación española' que organizaban Calvo y Pérez-Embid. Domínguez Marroquín admitía pacíficamente los postulados del régimen y trabajó en medios de comunicación relacionados con Falange. En cuanto a Amadeo de Fuenmayor, el secretario, era básicamente un jurista que se ordenaría sacerdote en 1949 y que, con el tiempo, llegaría a convertirse en una verdadera autoridad del Derecho Canónico; pero no estuvo adscrito a los planteamientos ideológicos de Calvo y Pérez-Embid. Algo sorprendente es que este último no se convirtiera en el presidente del consejo de administración de la nueva empresa (ya que podemos decir que era 'suya') y que se nombrara a alguien tan ajeno a sus planteamientos. La diferencia entre ambos en cuanto al número de acciones suscritas era pequeña. Parece algo buscado. Podemos preguntarnos el por qué. Quizá se quería distanciar la editorial -incluso estructuralmente- de unos planteamientos político-culturales concretos, que explicaremos más adelante. Eran los que asumían Pérez-Embid y Calvo Serer.

Álvaro del Portillo aportaba su antigua industria a la nueva sociedad anónima, pero mantenía la propiedad de la marca comercial 'Ediciones Rialp'. Cada cierto número de años - los que marcaba la ley- Álvaro del Portillo solicitaba puntualmente ante el ministerio de Industria la renovación de la marca. La última vez fue el 12 de mayo de 1967, cuando se le concedió por veinte años más. En 1976, siendo ya sucesor de Escrivá al frente del Opus Dei, cedió en la práctica la marca a Ediciones Rialp, S.A. Pero jurídicamente este hecho no se hizo efectivo hasta la fecha que correspondía por ley, es decir, el 12 de mayo de 1987, cuando la pudo transferir legalmente a la sociedad, y la

22 AGA. Escritura de constitución de Ediciones Rialp S.A., pp. 5-8. (3)000 62/06392. Carpeta Ediciones Rialp. 
editorial solicitó ya en nombre propio la siguiente renovación. ${ }^{23}$ Lo que en un principio establecía cierta relación - no reglada - entre la editorial y el Opus Dei, que quizá pudo ser una decisión prudente en 1948, con el paso de los años comenzó a perder su sentido, probablemente desde la década de los sesenta.

A lo largo del tiempo se fueron sucediendo distintas situaciones de relación entre el Opus Dei y Ediciones Rialp. Desde 1946 a 1953 puede afirmarse que la intervención de Escrivá o de Del Portillo en la vida y contingencias diarias de la empresa fue prácticamente nula, con tan solo una excepción: la sugerencia del primero a Jesús Urteaga ${ }^{24}$ de ampliar su estudio introductorio a El valor humano de lo santo (Bruckberger), ${ }^{25}$ y publicarlo por separado. Así nació El valor divino de lo humano, el libro de mayor venta de Rialp en toda su historia. La idea central de Bruckberger era que la santidad perfeccionaba al ser humano. La visión complementaria de Urteaga subrayaba el valor de lo humano en sí mismo, como una realidad querida por Dios, y asumible como legítimo camino de santidad en medio del mundo. Estamos cronológicamente ante el primer escrito inspirado directamente en el mensaje del fundador del Opus Dei. ${ }^{26}$

Escrivá, Del Portillo y algunos otros hombres y mujeres del Opus Dei se habían desplazado a Roma en 1946. Allí estuvieron ocupados en otras muchas cuestiones de mayor calado que las idas y venidas de los hombres de Rialp: las laboriosas gestiones jurídicas para lograr la aprobación definitiva de la Obra, las angustias económicas para pagar la casa de Roma, o los esfuerzos para la formación y expansión de los miembros del Opus Dei por varias naciones de Europa y América. No existen otros indicios documentales salvo los ya señalados, que relacionen durante estos años las decisiones empresariales de Rialp con Escrivá o Del Portillo.

Lo fundamental en la sociedad anónima fue asegurarse siempre una mayoría de accionistas a favor, un capital 'amigo' que asegurase el cumplimiento de los fines editoriales que se habían marcado sus directivos. Por ese motivo, durante los años cincuenta, las ampliaciones se realizaron para que los títulos fueran comprados por los ya accionistas. Y aunque se admitió a otras personas nuevas, siempre se procuró que un número adecuado perteneciera a la Obra y cubriera el $51 \%$ del dinero desembolsado. El resto lo adquirían simpatizantes o parientes, personas acordes con los objetivos de Rialp. Es un hecho documen-

23 http://consultas2.oepm.es/ceo/jsp/busqueda/consultaExterna.xhtml?numExp=M0197336 Consulta del día 22 de febrero de 2021. Es necesario aclarar que una es la fecha del documento, otra la de la tramitación y otra distinta la de la publicación. En este caso el 30 de septiembre del 1987 se resuelve lo solicitado el 12 de mayo, y es publicado en el Boletín de la propiedad mercantil el 11 de noviembre de 1987.

24 Jesús Urteaga Loidi (1921-2009). Doctor en Derecho Civil (Madrid, 1953) y en Teología (Roma, 1957). Sacerdote del Opus Dei. Dedicó parte de su actividad al periodismo, en TVE y en la revista Mundo Cristiano. Fue autor de varios libros de espiritualidad publicados por Rialp.

${ }_{25}$ Raymond Bruckberger (1907-1998), sacerdote dominico francés, llevó una vida ajetreada en la que se pueden incluir, además de sus libros de espiritualidad, la participación activa en la resistencia francesa durante la segunda guerra mundial y la dirección de películas de cine.

26 Illanes 2014, 466-467. tado que en 1961 el Opus Dei de España tuvo participación como tal en la empresa: concretamente un $1,5 \% .{ }^{27} \mathrm{Es}$ algo que no se volvió a repetir. Quizá en aquel momento se hizo necesario para alcanzar ese $51 \%$ del que hemos hablado.

Pero entre 1954 y 1964 podemos afirmar que el Opus Dei como tal se involucró en la marcha económica de Rialp. Cada semestre la editorial enviaba a Roma los balances, las cuentas de pérdidas y ganancias, el número de libros vendidos, las previsiones, el valor del almacén y todo tipo de detalles sobre la marcha económica de la empresa. ${ }^{28}$ Este comportamiento despareció por completo y de manera repentina en 1964 y no se volvió a repetir jamás. Da la impresión de un cambio de enfoque del Opus Dei (de Escrivá) respecto al seguimiento de este empeño apostólico que fue Ediciones Rialp. La tutela había terminado porque quizá nunca debió haber existido. Nos referiremos más adelante a las causas que motivaron este comportamiento atípico. La editorial fue evolucionando desde el punto de vista empresarial según cambiaban los tiempos. Con la llegada de la Ley Fraga conocemos todos los datos posibles sobre sus accionistas durante al menos diez años (1967-1977): quienes eran, donde vivían, cuantas acciones tenían, quien salía, quien entraba, quien subía en número de acciones, quien bajaba... Se comprueba así que el capital se hallaba muy repartido, habitualmente entre 100 y 140 personas individuales, con porcentajes en general pequeños o muy pequeños; y que, en cambio, existió siempre un grupo (entre cinco y siete personas) de miembros del Opus Dei que detentaban un número de acciones comparativamente mucho mayor que los demás, y que lograban con ello el control del capital. No existe ningún dato en la documentación que demuestre que el Opus Dei - como tal- animara a sus miembros o a otros amigos a invertir en Rialp. La impresión que se recoge es que son los propios directivos de la editorial los que decidieron qué tipo de políticas debían desarrollar para la atracción de capital. De la documentación obtenida en el Archivo General de la Administración se extraen los siguientes datos, que son aproximados, pues muchas veces no es posible asegurar la pertenencia al Opus Dei de los accionistas:

27 AGP. Fondo Ediciones Rialp. Datos económicos y publicaciones. G 889-II. Informe semestral julio-diciembre 1961, p. 34.

28 AGP. Fondo Ediciones Rialp. G-889-II. 1957. Datos económicos y publicaciones (contiene también los datos de 1955 y 1956)/ AGP. Fondo Ediciones Rialp. G-889-II. Datos económicos y publicaciones 1958 y 1959/ AGP. Fondo Ediciones Rialp. G-889-II- Datos económicos y publicaciones. Informe semestral junio de 1960/ AGP. Fondo Ediciones Rialp. Datos económicos y publicaciones. G 889-II. Informe semestral julio-diciembre 1961/ AGP. Fondo Ediciones Rialp. Datos económicos y publicaciones. G 889-II. Balance de situación a 30 de junio de 1962/ AGP. Fondo Ediciones Rialp. Datos económicos y publicaciones. G 889II. Informe semestral de Ediciones Rialp. Primer semestre de 1964. 
TABLA 1

Participación económica de miembros del Opus Dei en ediciones Rialp

\begin{tabular}{|c|c|c|c|c|c|c|}
\hline Fecha & No total accionistas & Del Opus Dei & $\%$ & $\begin{array}{c}\text { Accionistas } \\
\text { mayoritarios }\end{array}$ & Del Opus Dei & \% control capital \\
\hline $20-I I I-67$ & 128 & 25 & 19,5 & 7 & 7 & 36,35 \\
\hline $5-X-67$ & 122 & 27 & 22,13 & 7 & 9 & 37,37 \\
\hline $5-I V-68$ & 118 & 20 & 16,9 & 9 & 9 & 43,15 \\
\hline $20-I V-70$ & 135 & 29 & 21,48 & 11 & 5 & 50,54 \\
\hline $25-V-73$ & 136 & 30 & 20 & 6 & 9 & 42,45 \\
\hline $20-V I-74$ & 149 & 42 & 30 & 9 & 8 & 46,32 \\
\hline $1-I I I-75$ & 129 & 52 & 45,7 & 9 & & 8 \\
\hline $19-I-76$ & 126 & 53 & 44 & 9 & 46,48 \\
\hline
\end{tabular}

Fuente: elaboración de la autora a partir de AGA. ${ }^{29}$

Desde finales de los años cincuenta hasta su muerte (diciembre de 1974) fue presidente del consejo de administración Florentino Pérez-Embid el accionista mayoritario por aquel tiempo. Nadie le sustituyó como presidente cuando falleció, sino que Xavier Domínguez Marroquín (que siempre estuvo entre el pequeño grupo de accionistas con mayor capital) actuó como vicepresidente en funciones de presidente. Tras el fallecimiento de este fue nombrado José Antonio Ibáñez-Martín Mellado, ${ }^{30}$ que en aquellos momentos era dueño del mayor número de acciones.

En 1986, tras la primera quiebra de Rialp (debida a una contabilidad muy dudosa del departamento comercial) todos estos pequeños accionistas perdieron sus inversiones. ${ }^{31}$ La empresa pudo ser reflotada por la intervención de un hombre del mundo de las finanzas, Pablo Bofill de Quadras, miembro del Opus Dei que, entre sus negocios, se había

29 AGA 03/62/06392. Relación accionistas EDICIONES RIALP, S.A./ AGA 03/62/06392 Relación nominal de accionistas de Ediciones Rialp, S. A. Domicilios y números de acciones suscritas por cada uno de ellos/ AGA 03/62/06392 Relación de accionistas EDICIONES RIALP, S.A. Esta lista también se encuentra en AGA 03/62/06393/. AGA 3/62/06393. Nueva relación de accionistas de Ediciones Rialp, S.A. AGA 3/62/06393. Relación de accionistas de Ediciones Rialp, S.A./ AGA 03/62/06393. Relación actualizada de accionistas de EDICIONES RIALP, S.A./ AGA 03/62/06393. Relación de accionistas de EDICIONES RIALP, S.A./ AGA 3/62/06393. Relación actualizada de accionistas de EDICIONES RIALP, S.A.

30 José Antonio Ibáñez-Martín Mellado (Madrid, 1940). Ganó la cátedra de Filosofía en enseñanza secundaria en 1968. Y en 1980 la de catedrático de Filosofía de la Educación en la Universidad. Era hijo de José Antonio Ibáñez Martín, que fue ministro de Educación Nacional en los años cuarenta del siglo pasado. Precisamente invirtió en acciones de Rialp algún dinero que había heredado tras el fallecimiento de su progenitor.

${ }_{31}$ AGUN. Fondo Ediciones Rialp, S.A. Libro de Actas, número 3, pp. 65-67. Se cuenta con detalle el desarrollo de la Junta Extraordinaria de Accionistas, los motivos de la bancarrota y la sustitución de los pequeños accionistas por empresas ligadas a Bofill. Sobre las causas del fiasco se dice que la documentación entregada en los últimos años tanto al Consejo como a los accionistas, no reflejaba la auténtica situación de la sociedad, por lo que durante varios años (al menos desde 1984) se habían tomado decisiones empresariales sobre balances falseados. Se detectaron importantes desviaciones contables respecto de la realidad. Dichas desviaciones afectaban a partidas tanto del activo como del pasivo. La abultada cifra de pérdidas eran, en su mayor parte, ajenas a los resultados de explotación, y debidas a la mera regularización de esas desviaciones contables que se habían hallado. En cualquier caso, estaban en bancarrota. introducido en cierta medida en el mundo editorial. Bofill dirigía un complejo entramado de compañías que abarcaban desde bancos, hasta autopistas o negocios inmobiliarios. Buscando en todo momento el bien de Rialp, sustituyó a los pequeños accionistas por empresas de su entorno, que empezaron a tener así participación en el capital de la editorial. Simultáneamente se realizaron importantes inversiones para convertirla en una de las compañías más destacadas de España en cuanto a producción y venta de libros. Sin embargo Bofill, al no proceder del ámbito profesional de la edición, y no hallarse familiarizado con sus métodos (que poco tenían en común con los de otras empresas) puede afirmarse que tomó decisiones que no fueron las más acertadas. Además, el derrumbamiento simultáneo de su mosaico empresarial arrastró consigo a Rialp que nuevamente vio amenazada de forma muy grave su continuidad.

En esta situación agónica se hizo cargo de la empresa uno de sus directivos, Miguel Arango Fernández. ${ }^{32}$ Fue la crisis que se produjo entre 1993 y 1996. Con el consejo de Luis Valls, ${ }^{33}$ que dedicó buena parte de su tiempo libre al estudio de la situación económica de Rialp, y también con la ayuda de Rafael Termes, ${ }^{34}$ Miguel Arango consiguió ir desenredando la trama tejida en torno a la editorial, nunca realizada con mala intención, pero sí con ausencia de conocimientos sobre el ser de una empresa editorial. Nadie en el Opus Dei,

32 Miguel Arango Fernández (León, 1945), licenciado en Derecho, es un miembro del Opus Dei que llegó al mundo editorial en fecha un tanto tardía, pues se dedicó profesionalmente durante unos años a la dirección de diversas iniciativas de formación humana y cristiana promovidas por la Obra. Comenzó a trabajar con éxito en una pequeña editorial llamada Ediciones Auriga, dedicada a libros infantiles y juveniles, donde aprendió el oficio de editor. En 1987 entró en Rialp, fichado por Pablo Bofill, con el objetivo de sacar adelante una nueva línea Rialp-Junior y la colección estrella de esta, Ilamada 'El Roble Centenario'. Pronto llegó a ser director editorial de Rialp.

33 Luis Valls-Taberner (Barcelona, 1926-2006). Presidente del Banco Popular desde 1972 hasta 2004. Pidió la admisión en el Opus Dei en 1945. Licenciado en Derecho por la Universidad de Barcelona (1948) y doctor en Derecho por la de Madrid (1951).

${ }_{34}$ Rafael Termes Carreró (Sitges, 1918 - Madrid, 2005). Pidió la admisión en el Opus Dei en 1940, siendo el primer miembro de esta institución en Barcelona. Doctor Ingeniero Industrial. Consejero delegado del Banco Popular (1966-1977) y presidente de la Asociación Española de la Banca (AEB) desde su fundación en 1977 hasta 1990. Fue también profesor de finanzas en el IESE y director de su campus en Madrid. 
ningún director, ni de España ni de Roma, sugirió a Miguel Arango que se involucrara en el problema, qué debía o no hacer una vez metido en él, a quien debía o no pedir ayuda. Acudir a Valls-Taberner y a Rafael Termes fue una decisión tomada por el propio Arango, que conocía personalmente al primero y de manera algo lejana al segundo. Bajo su entera responsabilidad tomó las decisiones que creyó convenientes para solventar la situación. Contribuyeron a reconducir la editorial un grupo de supernumerarios antiguos en la Obra, que Termes ayudó a convocar. Pero aportaron su auxilio económico, o su tiempo, en la medida que cada cual entendió que podía o que quería hacerlo. No todos tenían en mente la misma visión respecto a Rialp que animaba a Miguel Arango. Para varios de estos colaboradores, quizá lo único importante era poder seguir editando las obras del fundador del Opus Dei y la colección Patmos. Pero el ADN de Rialp era otro. Fue Miguel Arango, en este sentido, quien decidió qué tipo de empresa editorial se iba a "resucitar»: la misma que había existido, que publicaba fundamentalmente libro de ensayo en Historia, Filosofía o Sociología y también editaba las obras de Escrivá, además de contar con prestigiosas colecciones de espiritualidad, poesía y cine. Quien no estuviera de acuerdo con este objetivo podía desentenderse de la tarea que no era precisamente fácil ni remunerada. ${ }^{35}$

Se consiguió ir desenredando los nudos y quedó como único administrador Miguel Arango Fernández. Bajo su dirección Rialp logró rebajar paulatinamente la deuda que arrastraba, haciéndolo poco a poco, ejercicio tras ejercicio, también mediante una política de edición muy bien pensada. Tras más de veinte años y ya con otro director general, Santiago Herraiz Solla, Ediciones Rialp es hoy una empresa saneada que, como dijimos al principio, ha logrado cumplir setenta años de vida.

Sin implicación económica por parte del Opus Dei, con una marca editorial que pertenece a Ediciones Rialp, de hecho desde 1976 y de derecho desde 1987, jurídica y económicamente, la relación de la empresa con la actual Prelatura es nula.

Pero tan importante como lo jurídico o lo económico es la orientación editorial. Josemaría Escrivá de Balaguer quería libros de buena calidad: buen contenido, buena presentación; libros de espiritualidad que atrajeran solo con mirarlos; libros sobre muchas disciplinas que ayudaran a orientar de manera cristiana la opinión pública. Pero nada más. O al menos no tenemos testimonio documental que aporte otros datos. La compra de 'Adonais' no fue idea suya. La colección 'El carro de estrellas', tampoco salió de su mente. La 'Biblioteca del Pensamiento Actual', no fue una sugerencia de Escrivá. Tampoco lo fue la colección Patmos de Espiritualidad. Tampoco pretendió que todos los miembros del Opus Dei publicaran en Rialp. Ni siquiera lo hizo Álvaro del Portillo cuando sacó al mercado su tesis doctoral en Historia, Descubrimientos y exploraciones en las costas de California, que editó el CSIC. Una tras otra, las colecciones que fueron marcando la existencia de Rialp a lo largo del tiempo, no tuvieron nada que ver con los gustos de Escrivá o, al menos, tampoco existe ningún documento que lo confirme. En

35 Conversación con Miguel Arango, Madrid, 29 de diciembre de 2015. cambio, si existe uno que explica claramente su deseo de realizar una buena enciclopedia católica, que - con el tiempo- sería la Gran Enciclopedia Rialp, otro éxito importante de la editorial. ${ }^{36}$

No parece, por tanto, que existiera por parte de Escrivá o del Opus Dei una orientación intelectual de las colecciones y los libros determinados. Rialp no era la presencia del Opus Dei en la vida intelectual española. En este tema, desde el principio, las decisiones las tomaron sus directivos. Cuando tuvo lugar el penoso incidente de la condena de La Virgen María por parte del cardenal Segura, ${ }^{37}$ Escrivá no ordenó la inmediata desaparición de la editorial o de la colección. Y motivos pudo tener porque una condena por modernismo en 1953, con la Obra recién aprobada, y un montón de calumnias expandidas por Roma (además de en España), no era un panorama muy alentador - quizá- para el futuro de la institución. Escrivá sí que sacó a Paniker de España e informó a Rialp que era mejor dejar para más adelante alguna publicación que este tenía prevista. Los motivos de estas decisiones pueden ser cuatro: el primero, la necesidad de que la editorial mantuviera, de momento, un perfil bajo; ${ }^{38}$ la segunda, quitar de en medio a una figura por la que sentían (¿rencor, envidia, celos, reserva?) ciertos ambientes eclesiásticos españoles; la tercera, aprovechar para que Paniker lograra un título oficial de doctorado en Teología por una Universidad romana, que no tenía y que era necesario que poseyera; y por último, acompañarle probablemente en su propia trayectoria vital y espiritual. Al año de llegar a Roma Escrivá envió a Paniker a la India, y ese fue el primer viaje a sus orígenes de este personaje que luego realizaría muchos más. Entre 1954 y 1966 Paniker fue y regresó de la India en varias ocasiones. Tuvo libertad, vivió a su aire, durante largas temporadas lejos de un centro de la Obra. Otros que viajaron como él a diversos países comenzaron allí la labor de la Obra. No fue el caso de Paniker en la India. Pero eso no obstaculizó su movilidad. Otros, antes que él, ya habían vivido aislados en naciones donde tardaría varios años en llegar la Obra. No era algo ajeno a la praxis del Opus Dei.

A partir de esa condena de La Virgen María (la primera gran crisis de Rialp) comenzó la revisión económica de la editorial y la revisión de los textos que hacían referencia a cuestiones doctrinales, teológicas, espirituales de los libros y prólogos escritos por miembros del Opus Dei. No se podía cometer otro error. En la actualidad, sin poder determinar cuando terminó esta tutela, el hecho es que ha desaparecido. ${ }^{39}$ Cada autor es dueño de su propio manuscrito y se maneja con él como estima conveniente.

\footnotetext{
36 AGP. Editoriales y distribuidoras. K 1, 215-3, p. 2.
}

37 Segura 1953.

38 Carta de Josemaría Escrivá a Antonio Pérez [responsable del Opus Dei en España en aquellos momentos], 22 enero 1954: «Di a Floro [Florentino Pérez-Embid] que no quiero que se publique nada de Ray [Raimundo Paniker], por ahora y en bastante tiempo", AGP, A. 3. 4., 265-4. Carta de Josemaría Escrivá a Antonio Pérez, 28 enero 1954: "A Floro, que conforme en cambiar a Ray de la editorial», AGP, A. 3. 4., 265-4. Carta de Josemaría Escrivá Amadeo de Fuenmayor y Antonio Pérez, 22 septiembre 1954: "Espero que reaccione bien, al fin [Paniker]. Yo lo quiero de veras y lo encomiendo mucho», AGP, A. 3. 4, 266-2.

39 Sí existe, en cambio, confirmación documental de cuando empezó (AGUN. Fondo Florentino Pérez-Embid. 003/007/009, p. 1). Se trata de un prólogo de Juan Bautista Torelló (1954) al libro La Virginidad. En una carta fechada el 12 de enero de 1954 afirma Torelló a los 
Respecto a la línea editorial, son sus directivos quienes velan por ella, no el Opus Dei. Se trata de seguir haciendo - cada vez de manera distinta, adaptándose a los tiemposlo que siempre se ha hecho, la idea con la que nació Rialp. Es razonable pensar que si cambiara perdería a sus lectores; mientras que no es probable que de hacerlo encontrara otros nuevos. Ediciones Rialp no se dedica a la ficción, que permite una gran variedad de títulos y por tanto unos lectores que pueden ser fieles a un escritor y desafectos a otro de la misma editorial. Ediciones Rialp, aunque tiene colecciones menos comprometidas en este sentido, se dedica a la alta divulgación de temas que a veces repercuten hondamente, con una visión cristiana amplia, no monolítica, en el sentido sobre la vida del ser humano y el acontecer de la sociedad.

Esta es la narrativa sobre Ediciones Rialp que proponemos en este estudio.

\section{LA NARRATIVA DEL ESTEREOTIPO ${ }^{40}$}

$Y$ es que no hay que olvidar que ya existe otra: la que podríamos denominar 'narrativa del estereotipo', un neologismo que podría definirse del siguiente modo: consiste en mantener en la escritura de la Historia ciertas ideas, quizá ya fosilizadas, basadas a veces en afirmaciones con poco rigor académico. Algo al modo de una 'leyenda negra' y que en el caso de Rialp podría describirse del siguiente modo: la Biblioteca del Pensamiento Actual es una herramienta utilizada por Rafael Calvo Serer y Florentino Pérez-Embid para difundir entre un público amplio y culto su concepto sobre España, o mejor dicho sobre el futuro de España. Esas ideas eran monárquico-tradicionalistas (no los Borbones, sino los Austrias), antiliberales por lo tanto, retrógradas puesto que regresaban a la primerísima edad moderna (el siglo de oro, la conquista de América), confesional-católicas como aquel imperio español y, quién sabe, si incluso partidarias de algo parecido al césaro-papismo. Es cierto que tal concepción, o al menos una parte, rondaba por la mente de ambos amigos, mucho más en el caso de Calvo Serer que de Pérez-Embid. Y puesto que los dos pertenecían al Opus Dei, se pretende que la institución se encontraba plenamente identificada con semejante planteamiento y además utilizó las vías que le brindó el CSIC para difundirlas en la sociedad. ${ }^{41}$ Pero el Opus Dei ni alentó ni desalentó estas teorías. No era su papel, porque la Obra - además de tener otros objetivos, de tipo espiritual cristiano- está compuesta por personas que en cuestiones político-ideológicas-profesiona-

de Rialp que en Roma le han suavizado un poco el texto. No obstante, en el que se publicó citaba tranquilamente a Freud y no de manera negativa.

40 Proviene del griego, de la palabra 'estereós' (sólido) y typos (molde). Su sentido general, según el DRAE es el de «Imagen, idea o noción inmutable que tiene un grupo social sobre otro, al que le son atribuidas de forma generalizada conductas, cualidades, habilidades o rasgos distintivos». Pensamos que puede aplicarse esta definición a nuestro caso de estudio y por ello hemos optado por el concepto «narrativa del estereotipo».

${ }^{41}$ Algunos autores se han alejado recientemente de este modo de ver: Díaz Hernández 2008; Prades Plaza 2015. Otros, sin embargo, partiendo de un concepto marxista de hegemonía, entendido como modo de controlar la sociedad a través de la cultura, siguen manteniendo este planteamiento: Castro Sánchez 2017. les pensaban (según ellos mismos han afirmados siempre) de manera libre. Por otra parte, la inmensa mayoría de los miembros del Opus Dei nunca estuvo inmersa en esta corriente, ni en ninguna otra, puesto que eran pocos lo que se sentían comprometidos con opciones político-culturales, del tipo que fueran. Centrándonos en los hombres que pilotaron Ediciones Rialp es necesario afirmar que existieron entre sus directivos todas las tendencias: desde falangistas de la vieja guardia como Domínguez Marroquín, a gentes sin ideología concreta como Amadeo de Fuenmayor, personas que admitían pacíficamente el franquismo, como Ismael Sánchez Bella, técnicos como Alberto Ullastres, liberales de viejo cuño (recordemos a Azcoaga) e incluso agnósticos o republicanos (José Luis Cano). Todos ellos fueron directivos o directores de colecciones. Pero parece que a Rialp nunca se le perdonará el éxito que cosechó la Biblioteca del Pensamiento Actual (BPA): ¿cómo algo, tan retrógrado, se presume que piensan sus detractores, pudo, a la vez, traer a España el desconocido ( $y$ valioso) pensamiento europeo de entreguerras? Puesto que se trata de una pregunta que exigiría una respuesta ponderada y atendiendo a muchos matices, quizá lo más práctico haya sido eludirla y sustituirla por el estereotipo. Por lo tanto, se quita importancia a esos autores europeos, dados a conocer en España por la BPA, etiquetándolos de conservadores, y se pone el acento sobre los otros libros de la colección, centrados en el pensamiento de la generación del 48 (que no fueron pocos). Así se fija una determinada narrativa, a la que hemos llamado «del estereotipo» muy común en la historiografía española hasta el siglo XXI, ${ }^{42}$ pero poco contrastada con el simple estudio de la historia del pensamiento europeo en la primera mitad del siglo XX.

Sin embargo, una vez centrados en la editorial, en sus sesenta años de vida, es fácil darse cuenta de que la BPA fue una aventura de jóvenes, llevada a cabo con la fuerza y el empuje que suele acompañar a esta etapa de la vida. Tuvo un comienzo impetuoso y un fin un tanto agónico, con un director cada vez menos interesado en ella, que evolucionó hacia otros planteamientos ideológicos y políticos y paulatinamente fue desentendiéndose de su creación de juventud. Pérez-Embid siguió manteniendo la BPA con el ímpetu que pudo, quizá de forma un tanto voluntarista, pero al cabo la colección terminó muriendo. Además, según pasaba el tiempo y como suele ocurrir habitualmente en la vida de personas y empresas, otros proyectos y otros planes editoriales muy distintos sustituyeron a los que hubo entre 1948 y 1953. En definitiva, la BPA reflejó en un buen número de sus volúmenes una concepción político-cultural concreta, pero que no fue la de Rialp como empresa ni, desde luego, la del Opus Dei. En este sentido, además, existen documentos de los primeros años en los que Florentino Pérez-Embid recordó varias veces - en tono fuerte- a Rafael Calvo Serer, que no confundiera la BPA con un instrumento de sus planes personales, ni comprometiera o involucrara a Ediciones Rialp en sus operaciones políticas. Rafael Calvo Serer tendía a mezclar todos los temas en sus cartas y quizá también en su pensamiento. Requirió la ayuda de Vegas Latapie para la

42 Que tales interpretaciones han llegado hasta nuestros días, lo demuestra una obra tan popular y polémica como la de Gregorio Morán 2014. También otras más ponderadas como las memorias de Carlos Robles Piquer 2011. 
BPA pero en realidad parecía que lo estaba haciendo para la editorial en sí misma. En una carta a este último, por ejemplo, hablando de su proyecto cultural, el catedrático valenciano abordaba cuestiones referidas a Arbor y a la 'nueva generación española', relacionando esta con la inminente aparición del primer libro de la BPA que incluiría un texto para 'presentar en sociedad' a la mencionada generación. ${ }^{43}$ La actitud de Pérez-Embid ante la actuación de Calvo Serer resultó seguramente un inesperado jarro de agua fría para este, además de una seria corrección:

Me preocupa eso de que digas que Eugenio considera importantísima nuestra empresa cultural. La personal tuya y mía, bueno. La Editorial, de ninguna manera. [...]. Conviene que nadie especule con la Editorial, que no está al servicio de nadie, y cuya labor no va a entrar en el juego de nadie. Ni siquiera en el tuyo o en el mío, personales. ${ }^{44}$

De modo que la manera de conducir la BPA que tenía Rafael Calvo Serer preocupaba a Pérez-Embid. Este último tenía muy claro que no se debía mezclar la Editorial con sus propias opiniones político-ideológicas-culturales. Rialp no podía hallarse ligada a ninguna propuesta de este tipo. Calvo y se encontraba en esos momentos en Gran Bretaña. Según las fuentes que poseemos Juan Antonio Galarraga (la persona que hacía cabeza en el Opus Dei en aquel país) habló personalmente con Rafael Calvo sobre este tema, recordándole que estaba «al servicio de la Editorial y de ... otras muchas cosas...», frase que puede hacer referencia a su condición de miembro de la Obra. Es como si le confirmara que era libre en su trabajo y en sus proyectos políticoideológico-culturales, pero sin olvidar que su vida tenía otro sentido más alto y que procurara ser más prudente, pues de su conducta no debía concluirse que la editorial o el Opus Dei formaran parte de la 'nueva generación'. Esta era la respuesta de Rafael Calvo Serer a Pérez-Embid, después de aquella conversación:

Ya hemos hablado con la machaconería y pesadez que me caracteriza, sobre esto. Completamente de acuerdo. La Editorial no está al servicio de nadie, y yo estoy al servicio de la Editorial. Mis gestiones han estado encaminadas a atraer intereses sin comprometer yo lo que no puedo comprometer. Juan A. [Antonio Galarraga] me añade que estoy al servicio de la Editorial y de... otras muchas cosas. ${ }^{45}$

Hay que reconocer, sin embargo, que en el affaire 'España sin problema-España como problema' Florentino PérezEmbid se dejó llevar por la fuerza emocional del momento. En esta ocasión concreta, ambos (Calvo y él) es probable que si comprometieran a la editorial. Antes de que terminara el año 1949 salió al mercado el cuarto libro de la BPA, una recopilación de artículos o ensayos previos de Rafael Calvo Serer que se llamó España, sin problema. Parece que hubo cierta prisa en su publicación, que coincide con el fin de las estancias europeas de Calvo y su asentamiento en Madrid. Es como si la presencia de este en España hubiera acelerado repentinamente los resortes para el lanzamiento, ahora de

43 AGUN. Fondo Rafael Calvo Serer. 001/029/0282, p. 2.

44 AGUN. Fondo Rafael Calvo Serer. 001/029/0293, p. 1. El subrayado en el original.

45 AGUN. Fondo Rafael Calvo Serer. 001/029/304, p. 1. verdad, de 'la nueva generación española'. Todos los textos del mencionado libro habían sido publicados previamente en $\operatorname{Arbor}^{46}$ o en el diario Ya. Alguno de ellos había sido traducido parcialmente al alemán y otro esperaba ser publicado también en francés en la revista Ecrits de París. El título del libro se debía al de uno de los ensayos, concebido como comentario a un libro de Antonio Tovar acerca de Menéndez Pelayo. Esta circunstancia y el hecho de que Pedro Laín Entralgo hubiera sacado a la luz, tan solo un año antes, un volumen titulado España como problema, provocó una de las polémicas ideológicas más enconadas del franquismo. El ejemplar de Arbor correspondiente a septiembre-octubre de 1949, números 45-46, Florentino Pérez-Embid realizaba un comentario del libro de Laín, y Rafael Calvo Serer otro sobre el de Tovar. El primero marcaba distancias entre la generación de los 'nietos del 98' [Laín y sus compañeros] y una nueva generación juvenil y rupturista con el pasado cultural y político [la de Arbor]. Ensalzó el magisterio y la sabiduría de Laín pero se lamentó del olvido de la revista Acción Española y de Maeztu. Por último, insistió elegantemente en que la generación de Laín, pensadores entre los 35 y los 50 años, debían dejar paso a la nueva generación, caracterizada por una nueva sensibilidad. «Con astucia, alabó el esfuerzo intelectual de Laín y, al mismo tiempo, escribió su epitafio... ${ }^{47}$

Calvo Serer, por su parte, se mostró menos sutil y atacó vehementemente la opinión de Antonio Tovar sobre Menéndez Pelayo, a quien el primero consideraba superado. Al entender Calvo que la ideología liberal era culpable de los totalitarismos del siglo XX, el joven catedrático defendía con pasión el antiliberalismo del polígrafo santanderino y su monarquismo tradicional, antiparlamentario y descentralizador, respetuoso con la personalidad de las regiones. Si Pérez-Embid y Calvo Serer pretendían mantener un debate amigable con las figuras más destacadas de la generación anterior hay que reconocer que la estrategia no resultó la más adecuada. O quizá la generación anterior no estaba acostumbrada a la crítica. Probablemente influyeron ambos factores.

Pero un hecho aislado no tiene la legitimidad suficiente para crear toda una teoría general que persiste hasta nuestros días. Sobre todo teniendo en cuenta que ambos grupos -falangistas y generación del 48- perseguían exactamente lo mismo: configurar España en torno a sus ideas o ideologías, ambas con mucho pasado pero con escaso futuro y donde la democracia estaba ausente.

Hay autores muy apegados a la narrativa del estereotipo. Hablando por ejemplo del ministerio Ruiz-Giménez (1951-1956), cuando se intentó desde Educación Nacional la apertura cultural, esta narrativa afirma de manera contundente que

46 La revista Arbor era el órgano oficial del CSIC. En aquellos momentos Rafael Calvo Serer era 'el director intelectual' de la revista, pero oficialmente solo su secretario; debido a sus abundantes estancias fuera de España, Florentino Pérez-Embid le sustituyó en este puesto. Se rodearon de intelectuales afines a sus ideas y Arbor se convirtió en un medio de difusión de las ideas de la 'generación del 48'. El director era José María Sánchez de Muniain, que a partir de 1951 trabajaría con Joaquín Ruiz-Giménez en el Ministerio de Educación Nacional. No siempre estuvo aquel de acuerdo con las teorías y prácticas de Calvo.

47 Díaz Hernández 2008, 231. 
la rivalidad política con el Opus Dei [de los falangistas 'liberales'] arrancaba de lejos y tuvo como episodio bien conocido el debate sobre el problema de España, pero ha de recrudecerse de modo dramático en este periodo concreto [ministerio Ruiz-Giménez], con la victoria por KO del nuevo catolicismo integrista de los santos hijos de Escrivá de Balaguer. ${ }^{48}$

Una afirmación muy sugerente pero sospechosa a ojos de un historiador. No hay que olvidar que su autor, Jordi Gracia, procede del ámbito de los estudios literarios o filológicos, de donde surgen los conceptos relacionados con las narrativas. Pero la historia exige rigor. Un historiador debería demostrar si los hijos de Escrivá eran santos o no, documentalmente; y si los que ganaron por KO eran hijos de Escrivá o no, también de forma documental. Aparte de todo ello, ¿qué significaba ganar por KO en esta disputa en el régimen de Franco referida a la apertura cultural? Si se quiere relacionar con la condena de Unamuno, parece que los obispos españoles no necesitaban el aliento de nadie para condenar a este autor. Así que quizá ganaron por KO los obispos y concretamente Pildain, que fue el encargado de redactar una pastoral contra el autor vasco de echarse a temblar. ${ }^{49}$

Siguiendo con lo que hemos llamado narrativa del estereotipo, Gracia afirma:

La emergente fuerza del Opus Dei cuenta con algunos órganos entonces prestigiosos como Ateneo, revista e institución bajo dominio opusdeísta, la revista Arbor y el ya antiguo control del CSIC que tanto irritaría a Antonio Tovar. Con él se alía el monarquismo restauracionista que por entonces defienden algunos de los más visibles miembros de la obra, como Rafael Calvo Serer y su Teoría de la restauración, y la tradición del catolicismo español más integrista que empezaba a editar por entonces Rialp — salvada la más flexible y abierta colección de espiritualidad Patmos, dirigida por Raimundo Paniker. ${ }^{50}$

El párrafo contiene unos cuantos datos que pueden resultar algo confusos, pues mezcla acontecimientos ocurridos en momentos muy distintos. Esto al historiador suele parecerle un desorden. Y dado que la cronología es importante para hacer historia, suele sacar una conclusión de imprecisión y desconcierto. Ateneo es muy posterior en el tiempo a Ediciones Rialp. Con la revista Arbor, del CSIC, ${ }^{51}$ ocurre lo mismo. En el CSIC, por otra parte, trabajaban cientos de personas, la inmensa mayoría de las cuales no pertenecía a la Obra. Si a Tovar la jefatura de Albareda (miembro de la Obra) le resultaba irritante, era su problema (de Tovar), pero no el de España en el siglo XX: es decir, no merece un comentario en un libro de historia. Pero además hay que

\section{Gracia García 2006, 143.}

49 Don Miguel de Unamuno, hereje máximo y maestro de herejías (Carta pastoral). 1953. Por Monseñor Antonio Pildain y Zapiain, Obispo de Canarias. Las Palmas de Gran Canarias: Imprenta del Obispado.

50 Gracia García 2006, 144.

51 El Consejo Superior de Investigaciones Científicas (CSIC) se fundó el año 1939 bajo el mandato de José Ibáñez Martín en el Ministerio de Educación Nacional. Su fin era la investigación científica en todas las ramas del saber. En cierto sentido venía a sustituir la labor de la Junta de Ampliación de Estudios y de la Institución Libre de Enseñanza. De hecho, ocupó sus edificios. Se quiso darle desde el principio una orientación cristiana, de acuerdo con las premisas de la «nueva Es paña» y al contrario de los planteamientos liberales y «anti católicos» de los que muchos acusaban a los hombres y obras de la Institución. recordar que los amigos falangistas de Tovar controlaban en aquellos momentos el Instituto de Estudios Políticos y la Editora Nacional, y habían controlado Escorial y otras revistas de gran calidad. No parece que a nadie de Ediciones Rialp le irritara eso. Al menos no existen testimonios ni en la bibliografía ni en la documentación. Y si por 'visible' miembro del Opus Dei se quiere dar a entender 'importante', hay que decir que Calvo Serer nunca tuvo ese carácter dentro de la Obra. No ocupó ningún puesto de dirección en ella.

Siguiendo con las afirmaciones de nuestro autor, este eclipse del falangismo intelectual "se sitúa en el contexto de una abierta pugna política e ideológica con el Opus Dei, repetidamente expresada en el semanario barcelonés [se refiere a Revista] y las revistas afines $" .^{52}$ Revista salió al mercado en abril de 1952. Según parece su novedad consistía

en que su línea editorial y política exige adoptar una actitud a favor o en contra, porque el futuro del país ha dejado de ser inmutable y perfecto para emerger en forma de conflicto público (es decir, político). 0 bien se suscribe la España sin problema de Rafael Calvo Serer y su entorno ideológico del Opus Dei, con publicaciones influyentes como Arbor y editoriales estimables como Rialp, o bien se acepta con Laín Entralgo España como problema. $^{53}$

De manera que son los falangistas intelectuales los que plantean claramente la división (conmigo o contra mi) y luego se quejan de que no todos estén con ellos. No parece una actitud muy liberal.

Insiste Gracia en que, «La divulgación de un pensamiento tradicionalista se realizó desde unas prensas muy concretas, las de la Editorial Rialp, y una colección muy divulgada, Biblioteca del Pensamiento Actual». Además, complementaria de la Biblioteca lo es la más combativa y coyuntural colección 'O crece o muere' del Ateneo, en las manos de Florentino Pérez Embid, a pesar del escándalo que su sectarismo inspira a Vicente Aleixandre, según registra José Luis Cano $(1986,40)$, y gracias al control de la dirección general de Propaganda - de quien depende el Ateneo-.

Si la BPA fue una colección muy divulgada sería porque la gente la compraba y lo hacía porque le gustaba. Por otra parte, lo que pudiera decir Aleixandre sobre el sectarismo de los demás, nunca podrá sobrepasar al suyo propio, del que dio tantas muestras el poeta, tan proclive a querer amañar los premios 'Adonais' según sus gustos y a insultar a cualquiera que no comulgara con sus planteamientos, especialmente los religiosos, sexuales y políticos (por este orden). Basta con leer los Cuadernos de Velintonia, de donde procede el dato que cita Gracia en el texto.

Para quien conozca por su propia investigación el periodo franquista, no le resulta sorprendente que la dirección del Ateneo conllevara otras influencias notables en la cultura del momento. Era la práctica habitual y por tanto la que siguió Pérez-Embid que, por cierto, ya entonces no era director de propaganda sino director de información. Algo que él mismo cambió. Los falangistas, anteriores ocupantes del mismo cargo, parece que estuvieron cómodos utilizando el término propaganda, y también irradiando sus ideas en los diversos ámbitos culturales.

\footnotetext{
52 Gracia García 2006, 15.
}

53 Gracia García 2004, 281. 
Según Gracia debemos a Ediciones Rialp la difusión de todo el integrismo que ha habido en España, pero también afirma este autor que el examen de la BPA nos

enseña los alicientes modernos y europeístas con que la Obra emprende la revitalización de lo que venía siendo el fundamento del nacional-catolicismo [...] [es significativa] la operación maquilladora con que se concibe la difusión de ese mismo pensamiento tradicional en la Biblioteca de Calvo Serer. ${ }^{54}$

Aquí se esconden varias contradicciones: primero, la Obra emprende, según este autor, una revitalización del nacional-catolicismo... La primera pregunta sería ¿para qué? Si eran lo más integrista del momento, según afirma Gracia, estarían encantados en pura lógica de seguir igual. Un integrista, por definición, no necesita revitalizar nada. Y, en segundo lugar, la cuestión más curiosa: ¿cómo pueden hacer algo que no necesitan, publicando además lo contrario de lo que piensan? Porque ahí entrarían todos esos libros con aliciente "moderno y europeísta» a los que se refiere Gracia.

Se hace necesario recordar, en este sentido, que el primer libro de la BPA fue una crítica durísima al nazismo nacida de la pluma de Romano Guardini. Todos los grupos culturales españoles la recibieron mal. Esto nos habla de dos cosas: de la orientación general de la intelectualidad española y de que - como operación de maquillaje- parece que la colección no empezó con éxito excesivo.

En resumen, la maliciosa maniobra 'make-up' de la BPA resulta demasiado complicada. Pero quizá sea la mejor manera de salir airoso del laberinto argumental en el que se ha introducido el propio Gracia. Porque se consiguió, según él, de la siguiente manera:

1. Los textos poco previsibles cumplen [en la BPA] la función testimonial de lo heterodoxo, típica de la casa. En el caso de la traducción póstuma de Els catalans al segle $X I X$, de Jaime Vicens Vives, en 1961, estrechamente vinculado a los grupos nacionalistas y cristianos catalanes [...]. También publica Rialp los nada vulgares Estudios sobre la palabra poética de José María Valverde, diez años antes, pero el grueso del catálogo recoge títulos que responden a los supuestos de una futura dominación católica. Por una parte, es intenso el esfuerzo difusor y cuidadosamente antologizador de las obras de Menéndez Pelayo, Donoso Cortés, Balmes, Antonio Aparisi, Vázquez de Mella o Ramiro de Maeztu. La reflexión política monárquico-restauracionista está en trabajos firmados por miembros más o menos reconocidos de la Obra como R. Gambra, López-Ibor, Santiago Galindo, Antonio Fontán, Jorge Vigón, Ángel López-Amo y, desde luego, F. Pérez Embid y R. Calvo Serer.

2. A esta trocha debe añadirse la nutrida representación de un pensamiento político europeo y conservador, no conflictiva con el propio ideario pero rentable. Terminaba así la imagen de una España culturalmente autárquica y se extendía la conciencia de una cierta modernidad alternativa. El último ingrediente de una línea editorial que no es azarosa lo suministra la extensa nómina de conferencia de 'O crece o muere'. Su relevancia específica no habría de levantar tampoco suspicacias demasiado profundas en el terreno ideológico o espiritual: Ignacio Agustí, J. M. Gironella,
Federico Sopeña, E. Moreno Báez, M. Baquero Goyanes, F. Ynduráin, José Luis Pinillos, Gerardo Diego, Pemán, Manuel Fraga, Vintila Horia, García-Viñó, etc. ${ }^{55}$

En la valoración de los párrafos anteriores, lo primero que podemos decir es que los textos de Vicens eran muy previsibles en la BPA. Él mismo fue buen amigo de PérezEmbid, precisamente por la visión de este, contrario a la idea del centralismo castellano en la Historia de España. PérezEmbid era partidario de que todas las regiones naturales deberían alcanzar el mismo peso. Esa sintonía de pensamiento no solo hizo que saliera en la BPA el libro de Vicens Vives - absolutamente sincero en el sentir de Pérez-Embid- sino otro volumen que recogía fragmentos de autores catalanes de gran importancia, como Francesc Cambó, y que Florentino precisamente se empeñó en sacar por encima de todo. Es decir, con lo catalán en Rialp nunca hubo maquillaje. Respecto al libro de Valente, muchos son los que manifiestan la sensibilidad poética y artística de Pérez-Embid. No hay que olvidar que su último cargo en el gobierno fue el de Director General de Bellas Artes. Es lógico que le apeteciera publicar en la BPA lo que él debió considerar un libro de ensayo con mucha calidad literaria. Sin embargo se negó a editar libros 'de su cuerda' que le proponía Calvo Serer (los de García Valdecasas) y era flexible a las opiniones de Fuenmayor que, como jurista, deseaba un libro adecuado de Derecho; como él mismo - Florentino- deseaba otro de Arte. Estos anhelos, sin embargo, no encontraron demasiado eco en Calvo Serer, que no realizó un gran esfuerzo para conseguir obras de este estilo. Por tanto, lo que algunos suponen un maquillaje es más lógico y razonable que sean distintos pareceres en torno a una misma colección. Calvo Serer, el director, quería dejarla bien enmarcada en sus opiniones e ideas; Pérez-Embid, el editor, mucho menos; por el contrario, deseaba abrirla a los temas esenciales de la cultura y de la sociedad. Había además otros directivos, como Amadeo de Fuenmayor o Alberto Ullastres, que positivamente no parecían conformes con reducir la BPA al pensamiento monárquico-tradicionalista de Calvo Serer y sus compañeros de generación. He aquí una explicación mucho más lógica y razonable de la variedad de la colección: distintas sensibilidades entre los hombres de la editorial, que en este tipo de negocios no suele ser extraña. Además hay que afirmar que a la relación de miembros de la Obra que hace Gracia le sobran cuatro nombres: Rafael Gambra, Santiago Galindo Herrero, Jorge Vigón y López-Ibor.

Que los pensadores europeos fueran poco conflictivos - según Gracia - solo demuestra que no conoce los problemas que tuvo el mencionado libro de Guardini. Pero conflictivos o no, los libros de la BPA decían cosas bastante más interesantes sobre la efervescente cultura europea del periodo de entreguerras, que las trasnochadas ideas que circulaban por España, en todos los grupos, fueran cuales fueran. Y si los volúmenes de la Biblioteca resultaron rentables, solo se nos ocurre pensar que las empresas, aunque sean editoriales, suelen abrirse para que no se hundan económicamente y por ello tienen cierta obligación de ganar dinero. Por último parece como si la línea de libritos ‘ $O$ crece o muere' fuera responsabilidad de Ediciones Rialp. No lo fue hasta finales de los años cincuenta - una década después

\footnotetext{
54 Gracia García 2006, 161
}

55 Gracia García 2006, 161-162 
de su fundación- cuando Pérez-Embid abandonó el Ateneo y se llevó con él la colección por él mismo fundada. Pero ya tenía por entonces Rialp otras muchas colecciones que en nada se parecían a esta, como 'La Empresa y el Hombre', materia auténticamente novedosa en España en aquellos momentos, dirigida por Miguel Siguán. 'O crece o muere' apenas llegó a ser una producción colateral.

En resumen: pensar que la BPA de Rialp es la causante de todos los problemas de la España franquista, entre ellos la longevidad del régimen, que todo el Opus Dei estaba de lleno introducido en tal menester y que se comportaron de forma artera y sectaria, resulta poco creíble por la misma complejidad de la operación. Rialp era por entonces una minúscula empresa, con el peligro constante de hundirse por falta de recursos. El Opus Dei estuvo centrado en aquellos esos años en su propio proceso jurídico de aprobación como institución de ámbito universal en la Iglesia. Y Escrivá de Balaguer abandonó España en 1946 para instalarse en Roma. Tampoco hay que olvidar que las comunicaciones eran difíciles, España se encontraba aislada del resto del mundo, etc. Recordamos estas cuestiones porque una operación de tal envergadura (controlar el Estado franquista) es muy difícil que pudieran hacerla únicamente Rafael Calvo Serer y Florentino Pérez-Embid. Quizá es justamente que otros con más medios quisieron realizarla y no pudieron porque era imposible. En esos casos viene muy bien tener a mano un chivo expiatorio para justificar los propios fracasos.

En este sentido, Eduardo láñez ha expuesto con amplitud las estrategias culturales que desarrollaron los llamados falangistas liberales (Laín Entralgo, Tovar, Ridruejo) y que no lograron el triunfo que esperaban. Así que, todo lo que después se llevó a cabo en cultura pudo parecerles un ataque a su acción, que querían exclusiva para ellos. Dice láñez:

En noviembre de 1940 aparecía Escorial como publicación periódica cultural y literaria de FET-JONS, y lo hacía merced a los deseos y esfuerzos de nombres estrechamente ligados a los servicios estatal-partidistas de Propaganda [...] desde el Ministerio de la Gobernación [...] el director de la revista era el mismísimo director general de Propaganda, Dionisio Ridruejo; su subdirector, Pedro Laín Entralgo, era jefe de la Sección de Ediciones, y dos de los nombres fundamentales de Escorial, los poetas Luis Felipe Vivanco y Luis Rosales -este último, además, secretario de redacción de la revista, eran los responsables, en aquella misma sección, de sendas líneas editoriales. Lo sorprendente, considerando estos nombres y su función, así como el ambiente de confianza que se respiraba entre el fascismo falangista español a la altura de noviembre de 1940 , es que se haya pensado siquiera en sus 'resultados finales' como en los de 'una revista liberal casi prototípica', y en el grupo como representante de un pretendido 'falangismo liberal' (cfr., respectivamente, Mainer 1971, 54 y Díaz 1983, 26-28). Según hizo observar no hace mucho el profesor Juliá (2004, 333-334), produce cierta 'sorpresa' que, usando un 'auténtico oxímoron', se defina a los componentes de ese grupo en 1940 como falangistas 'liberales' y reconstructores de una 'pretendida línea de continuidad, o de recuperación o de resistencia, de la tradición liberal española de antes de la guerra. ${ }^{56}$

\footnotetext{
56 láñez 2011, 91-92.
}

\section{LA NARRATIVA DEL SILENCIO}

Pero existe también una tercera narrativa, opaca, que podríamos denominar la narrativa del silencio. Simplemente no se habla de Rialp cuando hay que hacerlo, pero en cambio se habla de otros cuando consiguieron grandes hitos que ya antes habían sido cosecha de Rialp. Empezando por Adonais, se cuentan verdaderas maravillas sobre la colección y el premio de poesía joven, pero nadie recuerda que siguió existiendo - todavía hoy- porque lo compró un joven Ilamado Florentino Pérez-Embid cuando colección y premio estaban para pasar a mejor vida. Tan solo los autores que han escrito sobre Adonais para Rialp se han acordado del 'salvador'. Por el contrario, cuando se ha tratado de atacar al Opus Dei, enseguida han salido a la luz las 'malas artes' de Pérez-Embid, que negó el premio de 1949 a Blas de Otero por su Ángel fieramente humano, ${ }^{57}$ y que era a la vez un libro de planteamientos poco cristianos; ${ }^{58}$ o cuando los poetas catalanes (Barral, Gil de Biedma) organizaron a mediados de los 50 su cruzada personal contra «una colección editada por el Opus, de libros microscópicos e incoleccionables y en la que había que convivir con todos los Pérez de la cuerda granadina», según Barral. Y curiosamente Mainer realiza afirmaciones algo tajantes (que por supuesto no demuestra) pero de las que, en pura lógica, debería concluirse que el Opus Dei era la institución religiosa con mayor sensibilidad poética del momento. En concreto dice este autor: [El premio] «No se volvió a conceder hasta 1947, un año después de la compra de la colección por Editorial Rialp, el grupo pilotado por Florentino Pérez Embid y concebido por el Opus Dei como emblema de su presencia en la vida intelectual española»..$^{59}$ En pura lógica, si de la BPA se dice que expresaba el anti-progresismo político-cultural del Opus Dei, según algunos (y duró pocos años) ¿por qué de Adonais no va a poder afirmarse que demuestra la magnífica sensibilidad poética de la Obra, cuando además perdura en la actualidad?

Se olvida también con facilidad que fueron los libros de Rialp los primeros de la posguerra española que cuidaron decididamente el diseño, y optaron por una elegancia hasta entonces desconocida, un cuidado muy escogido de los tipos de imprenta, un inconformismo casi belicista contra el mal papel y las malas encuadernaciones. Por eso resulta chocante leer afirmaciones como la siguiente, referidas ya a los años 70: En Alfaguara, Salinas «descubrió la vía del gusto como fórmula comercial para alcanzar el favor del público".$^{60}$ Es cierto que los libros de Alfaguara fueron primorosamente diseñados. Pero había antecedentes 30 años antes: y esos fueron los volúmenes igual de primorosamente diseñados por Miguel Fisac, tanto para la BPA como para Patmos.

57 Mainer 2003, 20.

58 El poemario se publicó en Índice tiempo después. En este sentido, el censor del manuscrito escribió: «Las poesías de este libro están escritas de una forma tan extravagante, que al limitado criterio del lector le es difícil apreciar, si el nombre de Dios que aparece constantemente en ellas, es para venerarle o al contrario» Montejano 1998 , nota 6.

59 Mainer 2003, 17; Díaz de Castro 2003, 53-54; Ruiz Bautista $2008,88$.

60 Salinas 2013, 17. 
Similar sorpresa se siente cuando algunos autores afirman que Alianza Editorial (1966), fundada por José Ortega Spottorno, fue la primera en introducir en España el libro de bolsillo. Si los volúmenes de la BPA no eran libros de bolsiIlo, ¿qué eran entonces? ¿la Enciclopedia Británica? En este sentido leemos que esta editorial «hizo posible el libro de bolsillo de calidad en España». Y sigue Jaime Salinas, que era el editor:

En Alianza, donde queríamos hacer el libro de bolsillo, yo era muy consciente e insistía en que había que acabar con la imagen del libro gris, triste, de la Universal o la Austral, y hacer cubiertas atractivas, frescas, limpias, que entraran al comprador por los ojos. En parte, ése fue uno de los éxitos de Alianza. ${ }^{61}$

Las portadas fueron diseñadas por Daniel Gil. Resulta curioso que tanto Josemaría Escrivá como Jaime Salinas tuvieran las mismas ideas sobre la importancia capital del buen aspecto exterior del libro.

Igual de sorprendente son las afirmaciones que inciden en que la BPA fue una copia de la ya citada colección Austral, ${ }^{62}$ afirmación que se nos antoja una ocurrencia poco meditada. La cantidad de libros y temas publicados por la colección Austral, exceden ampliamente cualquier planteamiento de la BPA. Por otra parte su impresión era sucia - literalmente manchaba de tinta las manos del lector- y su encuadernación apenas parecía incoada: las páginas se desprendían nada más abrir los ejemplares. Y la colección Austral tenía unos objetivos de edición mucho más ambiciosos que la BPA de Calvo Serer. Publicó la primera todo tipo de libros, sin importar autor ni pensamiento. Y mucha literatura española, cosa que hay que agradecerle a Austral pero que jamás se planteó la BPA.

También observa el mismo autor que Rialp editaba libros del catolicismo español más integrista, salvo la colección Patmos de espiritualidad. Evidentemente la BPA sacó al mercado no solo a Menéndez Pelayo (un autor muy popular en todas las editoriales de pensamiento de los cuarenta), sino a Donoso Cortés o Ramiro de Maeztu. Muy cierto. Pero olvida el crítico que muchos volúmenes de la BPA, traducidos del alemán o del francés, e incluso del inglés o el italiano, no tenían nada que ver con ese integrismo tan desagradable, sino con corrientes bastante más abiertas del catolicismo europeo de la época. Aunque la BPA no publicó nunca a Maritain, tampoco lo hicieron hasta bien entrados los sesenta otras editoriales españolas. Sin embargo, gran parte de su círculo de amigos fueron editados por la Biblioteca del Pensamiento Actual y también por «la más flexible y abierta colección de espiritualidad de Patmos, dirigida por Raimundo Paniker.$^{63}$ Llega a decir Aranguren, hablando de Maritain, el 1 de febrero de 1953, que el auge del catolicismo seglar es menester apuntárselo a Maritain,

cualquiera que sea nuestro juicio sobre su nouvelle Chrétienté. Naturalmente, no todos nuestros «refutadores» del filósofo francés han visto esta dimensión positiva de su pensamiento. Sí, en cambio, Raimundo Paniker, y me complace reconocerlo así, tanto más cuanto que yo he discutido su pensamiento, con la

\footnotetext{
61 Salinas 2013, 60.

62 Gracia García 2006, 355.

63 Gracia García 2006, 143-144, 335.
}

provisionalidad y aun acaso la injusticia inherentes a toda crítica 'de oídas', sin texto escrito a qué atenerse. ${ }^{64}$

Parece, por tanto, que los hombres de Rialp estaban 'más avanzados' que los amigos de Aranguren en algunos aspectos del catolicismo, por ejemplo eran más proclives a los planteamientos 'maritenianos'. Porque, no lo olvidemos ni nos llamemos a engaño, Paniker y Calvo Serer eran en aquellos momentos uña y carne. Lo fueron desde que se conocieron en 1940. Y juntos visitaron por toda Europa a innumerables personajes que luego publicaron sus libros en Rialp.

A Raimundo Paniker le salvan algunos autores - Aranguren es uno- porque con ello aprovechan para atacar a Rialp y al Opus Dei, de manera indirecta. Paniker es el héroe que abandonó la Obra y eso ocurrió - deberíamos concluirporque su mente era más amplia, abierta, libre, que la de la institución y el resto de sus compañeros. En marzo del 1953 escribió Aranguren en su diario personal: «Desde hace algún tiempo la colección Patmos, acertadamente dirigida por Raimundo Paniker, subviene a una necesidad que nunca encareceremos bastante». Revisadas estas notas para su publicación, añade el pensador en 1978: «...en cuanto a Patmos, desde que dejó de ser dirigida por Paniker cayó en devocionalismo para uso de miembros del Opus Dei». ${ }^{65}$ Un comentario ciertamente despectivo, que además no se corresponde con la realidad, pero que deja en la cuneta $-\mathrm{y}$ sin rastro en la cultura - a Rialp, a Patmos y, de paso, al Opus Dei.

Esta acusación del devocionalismo aplicada a Patmos es también uno de los reproches preferidos por González de Cardedal. Como sus palabras fueron recogidas de la edición de un evento, podemos perdonar su falta de rigor en cuanto a fechas. ${ }^{66}$ El comienzo de Rialp o de Patmos está situado en los años cuarenta o en los cincuenta... a él eso parece resultarle indiferente, sin darse cuenta de que en el franquismo una década u otra, por juntas que estén, resultan tener diferencias cruciales. La conclusión a la que se llega es que tanto Rialp como otras editoriales (BAC, Gredos...), tuvieron una voluntad renovadora pero sin pretensiones:

Se comienza a traducir autores de espiritualidad y teología europea, hasta entonces casi desconocidos entre nosotros. Que el acento se pusiera a menudo en "fomentar la piedad» o "fundamentar la predicación de la Iglesia» llevó consigo el que quedaran en el olvido autores europeos de primer orden que no tuvieran esos objetivos entres sus prioridades, sino que se propusieron como meta primordial pensar la realidad cristiana en limpia gratuidad por ella misma, sus presupuestos, sus consecuencias y sus exigencias. Así por ejemplo quedaron inéditos en España autores claves de la conciencia católica moderna como J.H. Newman y M. Blondel. ${ }^{67}$

Newman era conocido en España desde principios del siglo XX y también lo publicó Rialp. Pero habría que decir que González de Cardedal se olvida de Guardini, uno de los primeros, si no el primero, que «pensó la realidad cristiana

\footnotetext{
64 López Aranguren 1994, 613-614.

65 López Aranguren 1994, 621.

66 González de Cardedal 2004

67 González de Cardedal 2004, 118-119.
} 
en su limpia gratuidad» ampliamente publicado por Rialp y por otras editoriales. Teniendo en cuenta la encíclica Humani Generis, los años de 'retiro' y sin escribir una línea de De Lubac y Congar, puede afirmarse que ya hicieron bastante las editoriales españolas traduciendo a autores católicos extranjeros, gente siempre 'algo sospechosa' para alguna jerarquía española. No se puede olvidar, en este sentido, el affaire Guitton, la condena por modernismo que sufrió Rialp por el libro de la colección Patmos La Virgen María. Aquello estuvo a punto de hundir la editorial. En el franquismo hay que ser capaz de calibrar los peligros de una época y de otra. Los años cuarenta no fueron los cincuenta ni desde luego los sesenta. Pero la realidad es que, en medio de todo, Patmos queda olvidada como la colección decisiva que en verdad fue en su momento, pareciendo al lector que se dedicó a publicar folletos sobre el rezo del santo rosario.

Pero es que en realidad de quien quiere hablar González de Cardedal es de Taurus, cosa normal pues las Jornadas se desarrollaban en torno a esta editorial. Aunque no sería necesario desmerecer la tarea de unos para cantar las glorias de otros. Y es evidente que Taurus las tuvo. Fundamentalmente publicó toda la obra de Karl Rahner, el corazón teológico de Taurus, en palabras de González de Cardedal. Pero, por desgracia, entre las cualidades de Rahner no estaba precisamente la necesidad de proponer el cristianismo como vida. No. Rahner fue un auténtico teólogo sistemático, cuyas obras poco tienen que ver con esa especie de vitalidad cristiana que más arriba ha recreado Cardedal. Sin embargo, en el intermedio, mientras se glorifican las publicaciones de Rahner en los sesenta, cae de nuevo en los brazos del olvido la labor de otras editoriales que en los años cuarenta y cincuenta se atrevieron con algunos autores por entonces poco convencionales.

\section{A MODO DE CONCLUSIÓN}

Con la perspectiva que dan 70 años de historia podemos observar que Ediciones Rialp contaba desde el principio con un proyecto editorial claro: libros de buen nivel divulgativo, en diferentes áreas, incluida una colección de espiritualidad, presentados de manera atrayente. $Y$ adecuándose en cada momento a las necesidades del mercado: una colección de actualidad político-cultural en los momentos primeros, de intensa ebullición política e intelectual en el país entre los propios partidarios del franquismo; libros de economía y empresa (desconocidos en buena medida en España), en el momento en que se apuntaba un desarrollo más allá de la autarquía; manuales universitarios que eran requeridos por profesores y alumnos, sobre todo desde el momento en que la Universidad española dejó de ser elitista; una Enciclopedia en el momento del triunfo de estas, que se convirtió en la más completa y galardonada escrita en castellano; la opción por los fascículos en el momento en que estos triunfaban... Sin que faltaran en toda su trayectoria los libros de ensayo sobre las cuestiones polémicas de cada tiempo, siempre con un orientaciòn cristiana amplia; los libros de espiritualidad, abiertos a las diferentes mentalidades acogidas en la Iglesia Católica, nunca en exclusiva a la del Opus Dei; y por último, la colección Adonais, presente desde el comienzo hasta nuestros días, por sí misma protagonista de buena parte de la poesía española del siglo XX y el actual. Es evidente la conexión primera de Rialp con el Opus Dei. Pero en la actualidad $-y$ desde hace años- esta no existe, aunque la empresa tiene una orientación cristiana clara, una propuesta para un mundo de corrientes múltiples y diversísimas. $Y$, en suma, contribuye a lo que es su fin propio: ayudar a tejer el entramado cultural de la sociedad

Empresarialmente habría que pensar quizá en quien acertó de veras en el complicadísimo sector editorial español: las compañías que cerraron; las que fueron vendidas a una multinacional en los años noventa ; o las que todavía hoy día siguen ocupando su espacio editorial (pequeño, mediano o grande), con una línea clara y una trayectoria independiente.

Por otra parte, parece que la historiografía española, quizá porque no existen estudios rigurosos sobre las distintas editoriales que marcaron época, repite afirmaciones sobre Rialp, o sobre otras empresas del sector, con datos parciales o sin pararse a contrastar. No ocurre lo mismo con las investigaciones centradas en el mundo editorial, aunque hay que afirmar que estos trabajos raramente se ven citados en obras de historia intelectual, cultural o política, salvo cuando se trata de cuestiones de censura. Pero el sector editorial aporta mucho más a la Historia de España que el mero hecho de haber sufrido la censura franquista, cuestión, por otra parte, que parece obvia en semejante régimen político.

La historia es una disciplina muy arraigada en los hechos avalados por los documentos. Así puede realizar sus afirmaciones, y dar lo seguro como seguro (mientras no aparezcan datos nuevos que puedan poner en duda esa seguridad). Lo demás pueden ser intuiciones, incluso muy acertadas, o afirmaciones que proceden de fuentes orales (generalmente opiniones) que se toman como argumentos decisivos. Quizá por ello no se debieran realizar 'préstamos' entre las diversas disciplinas académicas, por muy cercanas que se encuentren unas de otras. El concepto de 'narrativa' procede el ámbito de la literatura y se halla por tanto, muy cercano al de 'ficción'. Aplicarlo a la historia, puede resultar tentador pero debería también inquietarnos un poco. La historia rebusca lo nuevo o lo que quiere explicar mejor, en archivos a veces remotos, a veces poco accesibles y - siempre- muy fatigosos de consultar y trabajar, con muchos papeles polvorientos; por otra parte, es necesario contrastar esos nuevos conocimientos que nos brinda el archivo, con la tradición historiográfica sobre el tema, sin olvidar las fuentes orales cuando pueda contarse con ellas. Es la mente del historiador la que debe entender primero el complejo panorama que tiene delante, recomponer las piezas y lograr explicárselo a sí mismo, para después estar en condiciones de darlo a conocer.

\section{BibliografíA}

Barral, Carlos. 1982. Los años sin excusa. Memorias II. Madrid: Alianza Tres.

Cano, José Luis. 1986. Los cuadernos de Velintonia. Barcelona: Seix Barral.

Castro Sánchez, Álvaro. 2017. La Utopía reaccionaria de José Pemartín y Sanjuán (1888-1954): una historia genética de la derecha española. Cádiz: Servicio de Publicaciones de la Universidad de Cádiz.

Cruz Ruiz, Juan. 2014. Por el gusto de leer. Beatriz de Moura, editora por vocación. Barcelona: Tusquets Editores.

Díaz, Elías. 1973. «Notas para una historia del pensamiento actual español (1939-1972). Primera parte: los años cuarenta». Sistema. Revista de ciencias sociales 1: 107-132. 
Díaz de Castro, Francisco. 2003. «La colección Adonais en los años cuarenta». En 60 años de Adonais: una colección de poesía en España (1943-2003), coord. José Antonio Llera y Pureza Canelo, 31-56. Madrid: Devenir Ensayo.

Díaz Hernández, Onésimo. 2008. Rafael Calvo Serer y el Grupo Arbor. Valencia: Publicacions de la Universitat de València.

Escobar Laplana, David. 2012. Una colección para la transición. Espejo de España, de la Editorial Planeta (1973-1978). Gijón: Ediciones Trea.

Escolar Sobrino, Hipólito. 1999. Gente del libro. Autores, editores y bibliotecarios 1939-1999. Madrid: Editorial Gredos.

González de Cardedal, Olegario. 2004. «Un capítulo de la Teología en España». En Taurus. Cincuenta años de una editorial (1954-2004), coord. Antonio Lago Carballo. Madrid: Taurus.

González Gullón, José Luis. 2016. La Academia Residencia DYA (19341936). Su significado en la historia del Opus Dei. Madrid: Rialp.

Gracia García, Jordi. 2004. La resistencia silenciosa: fascismo y cultura en España. Barcelona: Anagrama.

Gracia García, Jordi. 2006. Estado y cultura. El despertar de una conciencia crítica bajo el franquismo, 1940-1962. Barcelona: Anagrama.

Herralde, Jorge. 2001. Opiniones mohicanas. Barcelona: El Acantilado.

láñez, Eduardo. 2011. No parar hasta conquistar. Propaganda y política cultural falangista: el grupo Escorial (1936-1986). Gijón: Ediciones Trea.

Illanes, José Luis. 2014. «Breve panoramica della bibliografia teologica su san Josemaría». En San Josemaria e il pensiero teologico. Atti del Convegno Teologico. Roma 14-16 novembre 2013, ed. Javier López Díaz. Roma: EDUSC.

Juliá, Santos. 2004. Historia de las dos Españas. Madrid: Taurus

Lago Carballo, Antonio, coord. 2004. Taurus. Cincuenta años de una editorial (1954-2004). Madrid: Santillana.

Lago Carballo, Antonio y Nicanor Gómez Villegas, eds. 2006. Un viaje de ida y vuelta. La edición española e iberoamericana (1936-1975). Madrid: Ediciones Siruela.

Larraz, Fernando. 2010. Una historia transatlántica del libro. Relaciones editoriales entre España y América latina (1936-1950). Gijón: Ediciones Trea.

López Aranguren, José Luis. 1994. Obras Completas, I. Madrid: Editorial Trotta.

Mainer, José Carlos. 2003. «El significado de Adonais». En 60 años de Adonais: una colección de poesía en España (1943-2003), coord. José Antonio Llera y Pureza Canelo 13-30. Madrid: Devenir Ensayo.
Mainer, José Carlos. 1971. «Prólogo». En Falange y literatura (antología), ed. José Carlos Mainer. Barcelona: Labor.

Martínez Martín, Jesús Antonio, dir. 2015. Historia de la edición en España (1939-1975). Madrid: Marcial Pons Historia.

Martínez de Sousa, José. 2015. Antes de que se me olvide. Una aventura tipográfica y bibliográfica personal e intransferible. Gijón: Ediciones Trea.

Montejano Gurruchaga, Lucía. 1998. «Blas de Otero y la censura española desde 1949 hasta la transición política». Revista de Literatura 120: 491-516.

Montero, Mercedes. 2017. «La editorial Minerva. Un ensayo de cultura popular y cristiana de las primeras mujeres del Opus Dei». Studia et Documenta 11: 227-266.

Moret, Xavier. 2002. Tiempo de editores. Historia de la edición en España, 1939-1975. Barcelon: Ediciones Destino.

Morán, Gregorio. 2014. El cura y los mandarines. Madrid: Akal.

Pérez Escohotado, Javier. 2002. Jaime Gil de Biedma. Conversaciones. Barcelona: El Aleph Editores.

Prades Plaza. 2015. España y su Historia: La generación de 1948. Castellón de la Plana: Universitat Jaume I.

Robles Piquer, Carlos. 2011. Memoria de cuatro Españas: monarquía, república, franquismo, transición. Madrid: Planeta.

Ruiz Bautista, Eduardo. 2005. Los señores del libro: propagandistas, censores y bibliotecarios en el primer franquismo (1939-1945). Gijón: Ediciones Trea.

Ruiz Bautista, Eduardo, coord. 2008. Tiempo de censura. La represión editorial durante el franquismo. Gijón: Editorial Trea.

Salinas, Jaime. 2013. Jaime Salinas: El oficio de editar. Una conversación con Juan Cruz. Madrid: Alfaguara.

Sánchez Vigil, Juan Miguel. 2009. La edición en España. Industria cultural por excelencia. Historia, proceso, gestión, documentación. Gijón: Ediciones Trea.

Segura, Pedro. 1953. "Carta Pastoral sobre la obra de Juan Guitton, titulada 'La Virgen María'». Boletín Oficial Eclesiástico del Arzobispado de Sevilla 1645: 414-481.

Soler Gimeno, Amparo. 2006. Conversaciones con editores. En primera persona, Amparo Soler. Madrid: Fundación Germán Sánchez Ruipérez.

Torelló, Joan Baptista. 1954. «Prólogo». En La Virginidad, Joseph Marie Perrin O.P. Madrid: Rialp.

Tusquets, Esther. 2005. Confesiones de una editora poco mentirosa. Barcelona: RqueR. 
